\title{
Cervical vertebral dislocation in a rugby player with congenital vertebral fusion
}

\author{
A.T. Scher, MB, ChB, DMRD \\ Department of Radiology, Tygerberg Hospital and University of Stellenbosch, South Africa
}

\begin{abstract}
Congenital cervical vertebral fusion is an anomaly which decreases the normal range of spinal movement and predisposes to trauma. The case history of a rugby player with a congenital fusion who sustained permanent quadriplegia after dislocation of the lower cervical spine is presented. The mechanism of injury is discussed. A plea is made for routine radiographic examination of the cervical spines of all rugby players in order to detect the presence of vertebral fusion and other conditions which may predispose to spinal trauma.
\end{abstract}

Keywords: Rugby, congenital vertebral dislocation, congenital vertebral fusion

\section{Introduction}

In a recent paper, I suggested that routine radiological examinations of the cervical spine be carried out on all rugby players ${ }^{1}$. This was with a view to detection of conditions which may predispose to cervical spine and spinal cord injury. One of the conditions which may be detected is congenital fusion (synostosis) of two or more cervical vertebrae. The majority of individuals with this congenital abnormality are asymptomatic and remain ignorant of their anomaly unless they undergo radiographic examination of the cervical spine.

I have previously reported on the effects of cervical spinal fusion in spinal injuries generally, and noted that the effect of fused vertebral bodies is to decrease the flexibility and normal range of movement of the cervical spine ${ }^{2}$.

During an analysis of injured rugby players admitted to the Conradie Spinal Cord Injury Centre with paralysis, it was noted that one player who suffered catastrophic spinal cord injury had in addition to the spinal injury, cervical vertebral fusion. The case history of this injured player is presented as an example of cervical spine injury in a patient with a pre-existing vertebral fusion and also to stress the importance of routine radiographic examination of all rugby players.

Address for correspondence: A.T. Scher, Department of Radiology, Tygerberg Hospital and University of Stellenbosch, PO Box 63, Tyerberg 7505, Republic of South Africa

C) 1990 Butterworth-Heinemann Ltd 0306-4179/90/030167-02

\section{Case history}

A 24 year old player, playing in his usual position as a prop forward in the front row of the scrum was injured when the scrum collapsed. His forehead struck the grass and while the rest of the pack pushed, his neck was forcibly flexed. He suddenly found himself to be paralysed and unable to move his limbs. He was immediately removed from the field. He was subsequently transferred to the Spinal Cord Injury Centre at Conradie Hospital.

On admission he was found to have complete quadriplegia with motor and sensory loss from the $C 7$ level. $X$-rays revealed congenital fusion of the vertebral bodies and posterior elements $C 2$ and $C 3$, (Figure 1) and anterior dislocation at the $\mathrm{C} 6 / \mathrm{C} 7$ level (Figure 2).

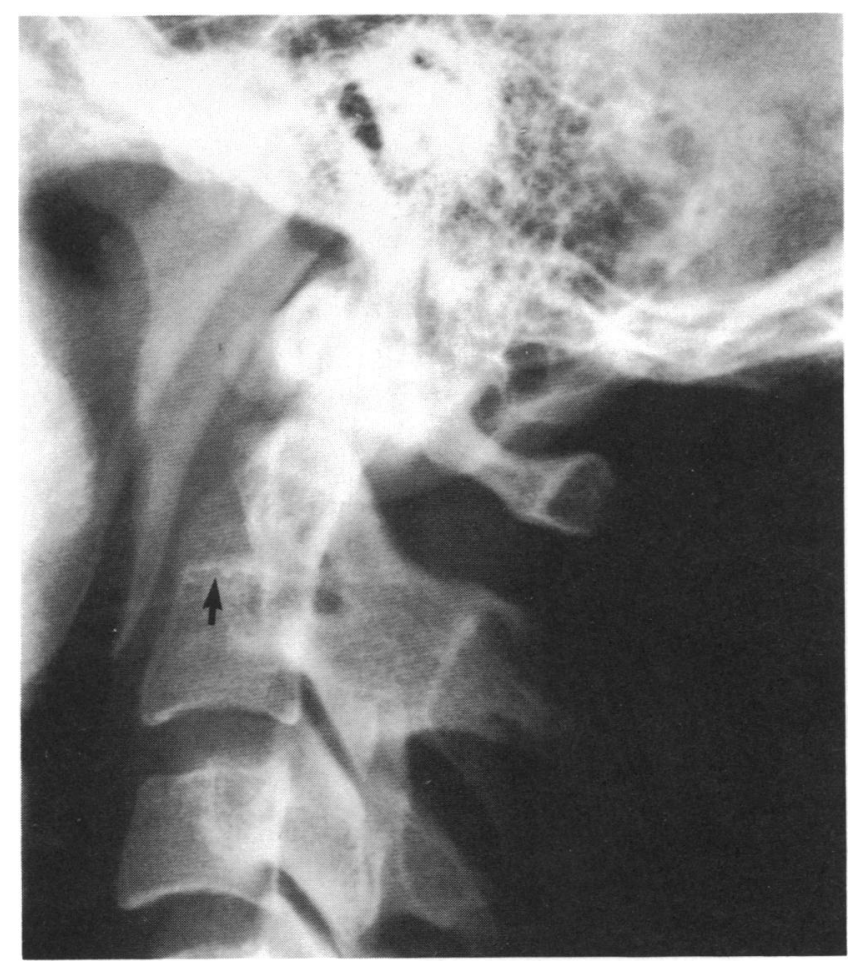

Figure 1. There is congenital fusion of the vertebral bodies and posterior elements of $C 2$ and $C 3$. Note the vestigial $\mathrm{C} 2 / \mathrm{C} 3$ disc space (arrowed) and the presence of two spinous processes 


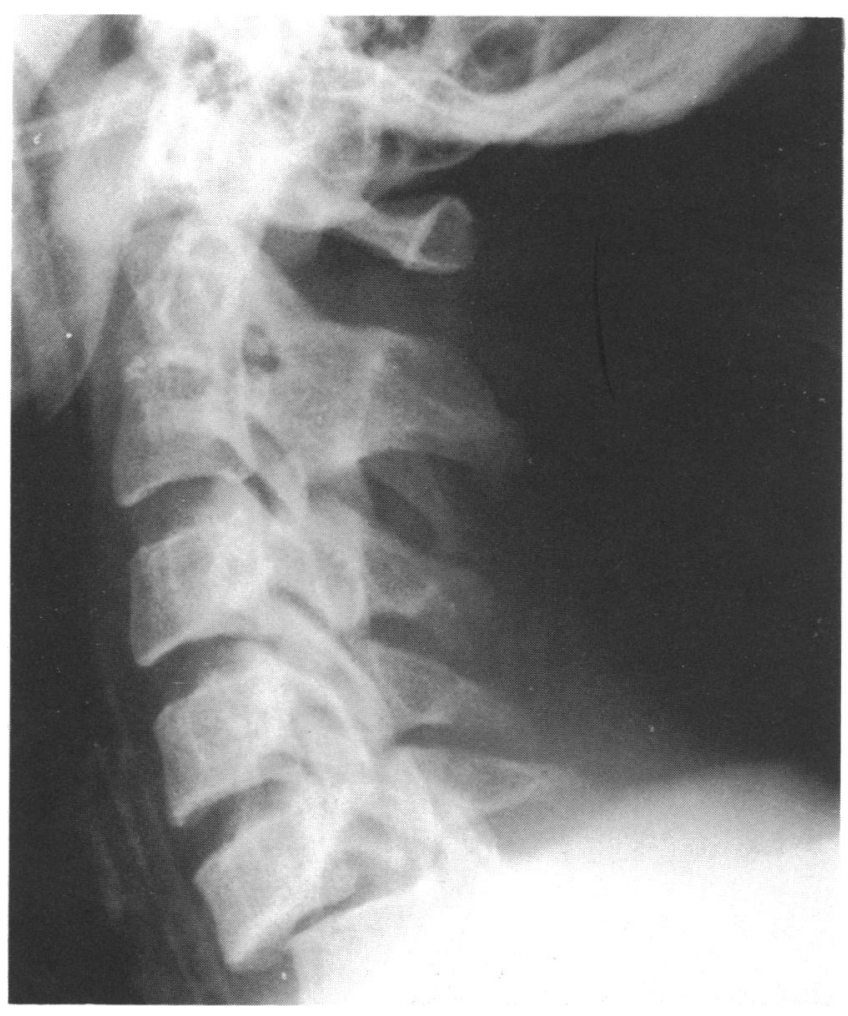

Figure 2. There is anterior dislocation of $\mathrm{C} 6$ on $\mathrm{C} 7$ with bilateral locking of facets. There is fusion of the second and third cervical vertebrae

He was treated by open reduction, wiring and bone graft at the dislocation site. Post-operative $x$-rays show satisfactory reduction and good alignment. No neurological recovery has taken place and the patient remains quadriplegic.

\section{Discussion}

\section{Mechanism of injury}

The mechanism of this patient's injury is typical of spinal injuries occurring due to collapse of the front row. Experimental study has shown that with the neck slightly flexed, and the vertex fixed on the ground, the normal cervical lordosis is lost and the spine straightened ${ }^{3}$. In this position, force is transmitted down the long axis of the spine. When the force exceeds the energy-absorbing capacities of the involved structures, dislocation may occur without fracture.

This patient's dislocation occurred at the $\mathrm{C} 6 / \mathrm{C} 7$ level while the congenital fusion involved $\mathrm{C} 2$ and $\mathrm{C} 3$. The part played by the fused vertical bodies in precipitation of the injury is therefore unclear. In the experimental work mentioned above, it was noted that when flexion force was applied to cadaveric specimens, extension of the upper cervical spine took place together with flexion of the mid-cervical region $^{3}$. The effect of the fused vertical bodies and posterior elements of $\mathrm{C} 2$ and $\mathrm{C} 3$ in this patient must therefore have produced some limitation of normal extension at this level.

Previous reports have shown that in patients with congenital fusion, the remaining free articulations are more susceptible to acute trauma due to the relative inflexibility of the cervical spine $e^{4}$. These subjects are particularly prone to hyperextension trauma. A simple fall, which for the normal subject would be harmless, may result in significant injury.

These findings have been confirmed in a recent paper analysing cervical spinal cord injury in American football players 5 . In this paper it is reported that five players with congenital cervical fusion sustained temporary paralysis after hyperextension injury.

It has been suggested that all rugby players participating regularly in club or social rugby, undergo radiological examination of the cervical spine at least once during their playing career ${ }^{1}$. A limited radiological examination of the cervical spine need consist of only a single lateral view. This is technically a simple, rapid, inexpensive (only one $x$-ray film is needed) examination and does not expose the player to excessive irradiation. The presence of cervical fusion or other significant abnormalities such as a congenitally narrow spinal canal or changes of degenerative disease would then be detected.

Awareness of the presence of these changes will enable a player, in consultation with his medical practitioner, to decide whether to continue his active rugby career. Should significant changes be present and, particularly if his playing position is that of a tight forward, he may well be advised to either cease playing or to change his playing position to one where his cervical spine is less exposed to stress.

\section{References}

1 Scher, A.T. Spinal cord injuries in rugby players J $S$ Afr Sports Med 1988, 3(2), 12-13

2 Scher, A.T. Cervical spine fusion and the effects of injury $S$ Afr Med J 1979, 56, 525-527

3 Bauze, R.J. and Ardan, G.M. Experimental production of forward dislocation in the human cervical spine $J$ Bone Jt Surg 1978, 60B (2), 239-245

4 Hensinger, R.N. and Deon, MacEwan. G. In The Spine' Philadelphia, W.B. Saunders, 1975, 179-181

5 Torg, J.S., Pavlov, H., Genuario, S.E. et al. Neurapraxia of ther cervical spinal cord with transient quadriplegia $J$ Bone Jt Surg 1986, 68A (9), 1354-1370 